\title{
Ivermectin for COVID-19: a broad-spectrum veterinary endectocide with antiviral activity
}

\author{
Khan Sharuna, CK Faslu Rahman ${ }^{\mathrm{b}}$, Bosco Jose $\mathrm{e}^{\mathrm{c}}$, Irshad Ad, Kuldeep Dhama ${ }^{\mathrm{e}}$, Ruchi Tiwari ${ }^{\mathrm{f}}$ and \\ Alfonso J. Rodriguez-Morales, ${ }^{\text {,h }}$
}

${ }^{a}$ Division of Surgery, ICAR-Indian Veterinary Research Institute, Izatnagar, Bareilly, Uttar Pradesh, India

${ }^{b}$ Division of Livestock Products Technology, ICAR-Indian Veterinary Research Institute, Izatnagar, Bareilly, Uttar Pradesh, India

'Division of Physiology \& Climatology, ICAR-Indian Veterinary Research Institute, Izatnagar, Bareilly, Uttar Pradesh, India

${ }^{\mathrm{d} C e n t r e ~ o f ~ E x c e l l e n c e ~ i n ~ M e a t ~ S c i e n c e ~ a n d ~ T e c h n o l o g y ~ a n d ~ D e p a r t m e n t ~ o f ~ L i v e s t o c k ~ P r o d u c t s ~ T e c h n o l o g y, ~ C o l l e g e ~ o f ~}$ Veterinary and Animal Sciences, Mannuthy, Thrissur, Kerala, India

${ }^{e}$ Division of Pathology, ICAR-Indian Veterinary Research Institute, Izatnagar, Bareilly, Uttar Pradesh, India.

fDepartment of Veterinary Microbiology and Immunology, College of Veterinary Sciences, UP Pandit Deen Dayal Upadhayay Pashu Chikitsa Vigyan Vishwavidyalay Evum Go-Anusandhan Sansthan (DUVASU), Mathura, India.

sPublic Health and Infection Research Group, Faculty of Health Sciences, Universidad Tecnologica de Pereira, Pereira, Colombia

${ }^{\text {h} G r u p o ~ d e ~ I n v e s t i g a c i o ́ n ~ B i o m e d i c i n a, ~ F a c u l t y ~ o f ~ M e d i c i n e, ~ F u n d a c i o n ~ U n i v e r s i t a r i a ~ A u t o n o m a ~ d e ~ l a s ~ A m e r i c a s, ~}$ Pereira, Risaralda, Colombia

Corresponding author: Khan Sharun email: sharunkhansk@gmail.com

Co-authors: CKFR: ckfaslurahman@gmail.com; BJ: jkjosek198@gmail.com; IA:irshad@kvasu.ac.in;

KD: $\underline{\text { kdhama@rediffmail.com; RT: ruchi.vet@gmail.com }}$

AJRM:arodriguezm@utp.edu.co

Received: 23-07-2020, Accepted: 16-08-2020, Published online: 06-09-2020

\begin{abstract}
Severe Acute Respiratory Syndrome coronavirus 2 (SARS-CoV-2) is a novel zoonotic coronavirus that has emerged from Wuhan, China. Compared to its predecessors, Severe Acute Respiratory Syndrome CoV (SARS-CoV) and Middle East Respiratory Syndrome CoV (MERS-CoV), SARS-CoV-2 has exhibited efficient human-to-human transmission. In addition to the efficient human-to-human transmission, SARS-CoV-2 is also reported to infect other animal species such as cats, tigers, lions, dogs, and minks. The susceptibility of other felines such as cheetah, puma, jaguar, leopard, and lynx are unknown. The reports of SARS-CoV-2 natural infection in animals opens up several oppurtunities to identify suitable animal models for the evaluation of SARS-CoV-2-specific vaccines and therapeutics. Ivermectin is a macrocyclic lactone endectocide that has broad-spectrum anti-parasitic activity. The wonder drug ivermectin was also found to possess antiviral, anti-bacterial, and anti-cancer activity. The antiviral activity exhibited by ivermectin against SARS-CoV-2 is believd to be mediated via targeting the importin $\alpha / \beta$-mediated nuclear transport and requires further validation. Since, the antiviral activity of ivermectin is through a host-directed mechanism, it can reduce the viral load even if administered at a lower dose. Further studies are required to evaluate the efficacy of ivermectin based on in vivo as well as the clinical trials. Being an FDA approved antiparasitic drug, repurposing it for treating COVID-19 patients will be an easy task once it is found to have therapeutic potential.
\end{abstract}

Keywords: Ivrmectin; SARS-CoV-2; COVID-19; Repurposed drugs; Therapeutics; Antiviral drug

doi: https://doi.org/10.51128/jfas.2020.A001| How to cite this article: Sharun K., Faslu Rahman CK, Jose B., Irshad A., Dhama K., Tiwari R., and Rodriguez-Morales, A.J. 2020. Ivermectin for COVID-19: a broad-spectrum veterinary endectocide with antiviral activity, Journal of Food and Animal Sciences, 01(01): 01-06.

Copyright: Sharun, et al. Open Access. This article is distributed under the terms of the Creative Commons Attribution 4.0 International License (http://creativecommons.org/licenses/by/4.0/), which permits unrestricted use, distribution, and reproduction in any medium, provided you give appropriate credit to the original author(s) and the source, provide a link to the Creative Commons license, and indicate if changes were made. The Creative Commons Public Domain Dedication waiver (http://creativecommons.org/publicdomain/zero/1.0/) applies to the data made available in this article, unless otherwise stated. 


\section{Introduction}

Severe Acute Respiratory Syndrome coronavirus 2 (SARS-CoV-2) is the third zoonotic coronavirus (CoV) after Severe Acute Respiratory Syndrome CoV (SARS-CoV) and Middle East Respiratory Syndrome CoV(MERS-CoV) (Dhama et al., 2020a; Malik et al., 2020a). SARS-CoV-2 has exhibited very high transmission potential among human beings (Dhama et al., 2020a). Bats are considered to be the reservoir host and the most probable source of origin in case of SARS-CoV-2 (Malik et al., 2020a). The genome of SARS-CoV-2 was found to be more similar to SARS$\mathrm{CoV}$ than MERS-CoV at the nucleotide level (Sharun et al., 2020a). In addition to the efficient human-tohuman transmission, SARS-CoV-2 is also reported to infect other species such as cats (Rodriguez-Morales et al., 2020), tigers, lions (Sharun et al., 2020b), dogs, and minks (Dhama et al., 2020b; Tiwari et al., 2020). The superior tranmsmission potential exhibited by SARS-CoV-2 as compared to SARS-CoV and MERS$\mathrm{CoV}$ warrants the need for implementing biosafety and biosecurity measures to control and prevent the disease transmission among human beings and animals (Ahmad et al., 2020; Sivaprasad et al., 2020).

Researchers are trying to develop SARSCoV-2-specific vaccines and therapeutics to counter this pandemic. A few of these candidate vaccines and therapeutics are already undergoing clinical trials and have shown promising results(Haritha etal., 2020; Malik et al., 2020b; Patel et al., 2020). Some of the repurposed drugs include ivermectin, dexamethasone, ebselen etc (Haritha et al., 2020; Sharun et al., 2020c; Sharun et al., 2020d). Antibody-based immunotherapeutic strategies such as convalescent plasma and monoclonal antibodies was found to be associated with reduction in the mortality rate among COVID-19 patients (Sharun et al., 2020e).

The review is aimed to analyze and evaluate the potential of ivermectin as an antiviral agent against SARS-CoV-2. We have also discussed in brief about the occurance of SARS-CoV-2 infection in animal species.

\section{COVID-19 in animals}

Although several reports of SARS-CoV-2 infection has been reported in companion animals like dog and cats, none of them could establish the effective transmission of this novel virus from animals-tohumans (Sharun et al., 2020a; Tiwari et al., 2020). On $4^{\text {th }}$ April 2020, the first case of COVID-19 in zoo animals was confirmed in a Malayan tiger maintained at the Bronx Zoo, New York (CDC, 2020). The samples were taken for testing when several big cats started showing signs of respiratory illness. Recently another four tigers and three lions from the same zoo were tested positive for COVID-19, increasing the total number of SARS-CoV-2 positive zoo animals to eight (National Geographic, 2020). Experts believe that these big cats got the disease from a COVID-19 positive zoo employee (CDC, 2020). Even though several animals exhibited clinical signs, samples from only one tiger were collected for testing as it required general anesthesia (Shi et al., 2020). Later, additional tests were done in the suspected animals using fecal samples (National Geographic, 2020).

The potential for animal-to-animal transmission has already been reported in cats under experimental conditions (USDA, 2020). Therefore, social distancing has to be followed not only in human beings but also for animals, especially those animals that are maintained in zoos. Big cats living in confined enclosures are at higher risk of getting COVID-19. Even though animal-to-animal transmission is not reported under natural conditions, the possibility for the same cannot be ruled out. The occurrence of SARS-CoV-2 infection in the captive population of big cats gives us a hint on the possibility of disease spillover to the wild populations of tigers and lions. Such a scenario will threaten the survival and damage the future of these wild animal species. As of now, domestic cat, tiger, and lions are found to be susceptible to SARS-CoV-2 infection. The susceptibility of other felines such as cheetah, puma, jaguar, leopard, and lynx are unknown. The reports of SARS-CoV-2 natural infection in animals opens up several oppurtunities to identify suitable animal models for the evaluation of SARS-CoV-2-specific vaccines and therapeutics. The efficacy and safety of COVID-19 vaccines are mainly evaluated using non-human primates, Rhesus macaque (Macaca mulatta) and Cynomolgus macaque (Macaca fascicularis) (Faslu Rahman et al., 2020; Sharun et al., 2020b).

\section{Ivermectin for COVID-19}

Caly et al. (2020) recently reported that the veterinary drug ivermectin exhibited in vitro antiviral activity against SARS-CoV-2, the virus responsible for Coronavirus disease 2019 (COVID-19). This is a proud moment for veterinary dermatologists around the world. Ivermectin, a macrocyclic lactone endectocide, is considered as the "wonder drug" in veterinary dermatology due to its broad-spectrum anti-parasitic activity. This great drug was first introduced to the animal health market as an endectocide in the year 1981 (Omura and Crump, 2014). Following its commercialization. Ivermectin was initially used as an endectocide that is effective against both ectoparasitic arthropods and endoparasitic nematodes of animals (Sharun et al., 2019a). Ivermectin has been used in therapeutics of parasitic skin conditions such as 
demodicosis and sarcoptic mange with excellent efficacy (Paterson et al., 2009; Vine et al., 2010; Sharun et al., 2019a). The antiparasitic activity of ivermectin is mediated by selectively binding to the glutamate-gated chloride channels, thereby increasing the permeability of chloride ions resulting in motor paralysis and death (Omura and Crump, 2014).

However, as time passed, ivermectin was found to possess anti-viral, anti-bacterial, and anti-cancer potential that further extended the activity spectrum of this wonder drug (Omura and Crump, 2014; Sharun et al., 2019b). During the past 40 years following its introduction, ivermectin has been extensively evaluated as a repurposed therapeutic drug against several bacterial and viral diseases of both animals and human beings (Crump, 2017). The clinical utility of ivermectin has significantly been hampered due to its potential for cytotoxicity. However, this can be controlled by changing the vehicles used in the formulations, thereby modifying the pharmacokinetic properties of the drug (Sharun et al., 2019b).
The broad-spectrum antiviral activity exhibited by ivermectin against several animal and human viruses are mediated via targeting major components/processes like importin $\alpha / \beta$-mediated nuclear transport, nuclear import of UL42, NS3 helicase, and nuclear localization signal-mediated nuclear import of Cap (Sharun et al., 2020c). However, the antiviral activity exhibited by ivermectin against several RNA viruses is mediated by the inhibition of importin $\alpha / \beta$-mediated nuclear transport (Crump, 2017). An analogous process has been suggested for the anti-SARS-CoV-2 activity exhibited by ivermectin and requires further validation (Caly et al., 2020). The antiviral activity of ivermectin is mediated by directly targeting a key cellular process of the mammalian cell instead of the virus. Being a host-directed agent (HDA), administration of ivermectin at lower doses will be sufficient enough to reduce the viral load by a modest amount. This will give sufficient time for the body's immune system to mount full scale antiviral response against SARS-CoV-2 (Bray et al., 2020).

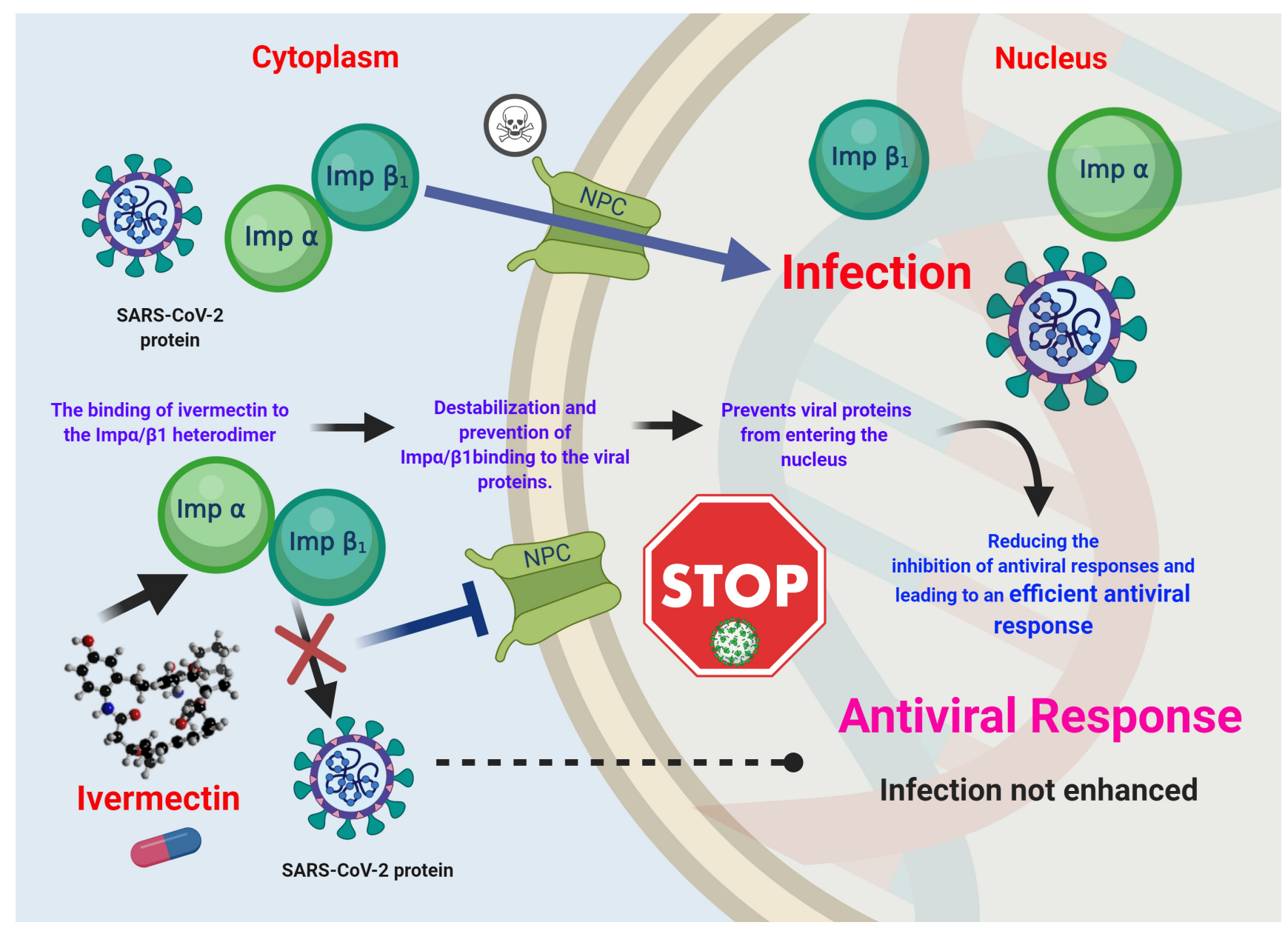

Figure 1: Ivermectin exerts antiviral activity aginst SARS-CoV-2 via targeting the importin $\alpha / \beta$-mediated nuclear transport. IMP $\alpha / \beta 1$ binds to the $\mathrm{CoV}$ protein in the cytoplasm and translocate it through the nuclear pore complex (NPC) into the nucleus leading to enhanced infection. Ivermectin binds and destabilises the $\operatorname{Imp} \alpha / \beta 1$ heterodimer thereby preventing Imp $\alpha / \beta 1$ from binding to the viral protein and preventing it from entering the nucleus thereby leading to efficient antiviral activity. 


\section{Conclusion and future prospects}

The increasing reports of COVID-19 in animals, especially in zoo animals, should be considered as a matter of great concern in terms of animal health, welfare, and wildlife conservation. The recent developments in the animal susceptibility to COVID-19 calls for the implementation of strict surveillance and routine screening in zoo animals all around the world. In addition to the disease surveillance in zoo animals, zookeepers and employees should be screened to prevent the possibility of humanto-animal transmission. Taking into consideration the susceptibility of felines to SARS-CoV-2, disease surveillance and screening should be extended to the other members of the family Felidae.

Further studies are going on at the moment to evaluate in vivo as well as the clinical utility of ivermectin to counter this pandemic virus. Being an FDA approved antiparasitic drug, repurposing ivermectin for the treatment of COVID-19 patients will be an easy task if found useful in the clinical trials. Apart from the well-established clinical utility in veterinary dermatology clinics, ivermectin will continue to surprise the scientific world by further expanding its activity spectrum against diverse ranges of emerging and re-emerging diseases.

\section{Authorship contribution statement}

Khan Sharun: Conceptualization, Methodology, Formal analysis, Investigation, Writing - original draft, Writing - review \& editing. C. K. Faslu Rahman: Software, Writing - review \& editing. Bosco Jose: Writing - review \& editing. Irshad A: Writing - review \& editing. Kuldeep Dhama: Writing - review \& editing. Ruchi Tiwari: Writing - review \& editing. Alfonso J. Rodriguez-Morales: Writing - review \& editing.

\section{Acknowledgments}

All the authors acknowledge and thank their respective Institutes and Universities.

\section{Funding}

This compilation is a review article written by its authors and required no substantial funding to be stated.

\section{Declaration of Competing Interest}

All authors declare that there exist no commercial or financial relationships that could, in any way, lead to a potential conflict of interest.

\section{References}

Ahmad T. Haroon, Dhama, K., Sharun, K., Khan, F.M., Ahmed I., Tiwari, R., Musa, T.H., Khan, M., Bonilla-Aldana, D.K., J. Rodriguez-Morales A., and Hui, J. 2020. Biosafety and biosecurity approaches to restrain/contain and counter SARS-CoV-2/COVID-19 pandemic: a rapidreview. Turk J. Biol. 44(3):132-145. doi: 10.3906/ biy-2005-63.

Bray, M., Rayner, C., Noël, F., Jans, D., and Wagstaff, K. 2020. Ivermectin and COVID-19: A report in Antiviral Research, widespread interest, an FDA warning, two letters to the editor and the authors' responses. Antiviral Res. 178: 104805. doi: 10.1016/j.antiviral.2020.104805

Caly, L., Druce, J. D., Catton, M. G., Jans, D. A., and Wagstaff, K. M. 2020. The FDA-approved drug ivermectin inhibits the replication of SARSCoV-2 in vitro. Antiviral Res. 178: 104787. doi: 10.1016/j.antiviral.2020.104787

CDC. 2020. https://www.cdc.gov/coronavirus/2019ncov/daily-life-coping/animals.html (Accessed on April 25, 2020)

Crump, A. 2017. Ivermectin: enigmatic multifaceted 'wonder' drug continues to surprise and exceed expectations. J. Antibiot. 70(5): 495-505.

Dhama, K., Khan, S., Tiwari, R., Sircar, S., Bhat, S., Malik, Y.S., Singh, K.P., Chaicumpa, W., BonillaAldana, D.K., Rodriguez-Morales, AJ. 2020a Coronavirus Disease 2019-COVID-19. Clin Microbiol Rev. 2020a. 33(4):e00028-20. doi: 10.1128/CMR.00028-20.

Dhama, K., Patel, S.K., Sharun, K., Pathak, M., Tiwari, R., Yatoo, M.I., Malik, Y.S., Sah, R., Rabaan, A.A., Panwar, P.K., Singh, K.P., Michalak, I., Chaicumpa, W., Martinez-Pulgarin, F.D., Bonilla-Aldana, D.K. and Rodriguez-Morales, A.J. 2020b. SARS-CoV-2 jumping the species barrier: Zoonotic lessons from SARS, MERS and recent advances to combat this pandemic virus. Travel Med Infect Dis. 37:101830. doi: 10.1016/j. tmaid.2020.101830.

Faslu Rahman, C., Sharun, K., Jose, B., Sivaprasad, M., and Jisna, K. 2020. Animal Models for SARS-CoV-2 Infection: A Tool for Vaccine and Therapeutic Research. Trends in Biomaterials \& Artificial Organs, 34(S3): 78-82.

Haritha, C.V., Sharun, K. and Jose B. (2020). Ebselen, a new candidate therapeutic against SARS-CoV-2. International Journal of Surgery, 84: 53-56. doi: 
10.1016/j.ijsu.2020.10.018.

Malik, Y.S., Sircar, S., Bhat, S., Sharun, K., Dhama, K., Dadar, M., Tiwari, R. and Chaicumpa, W. 2020a. Emerging novel coronavirus (2019-nCoV)-current scenario, evolutionary perspective based on genome analysis and recent developments. Vet Q. 40(1):68-76. doi: 10.1080/01652176.2020.1727993.

Malik, Y.S., Ansari, M.I., Ganesh, B., Sircar, S., Bhat, S., Pande, T., Vinodhkumar, O.R., Kumar, P., Iqbal Yatoo M., Tiwari, R., Touil, N., Patel, S.K., Pathak, M., Sharun, K. and Dhama, K. 2020b. BCG vaccine: a hope to control COVID-19 pandemic amid crisis. Hum Vaccin Immunother. 29:1-9. doi: 10.1080/21645515.2020.1818522.

National Geographic. 2020. Seven more big cats test positive for coronavirus at Bronx Zoo https://www.nationalgeographic.com/ animals/2020/04/tiger-coronavirus-covid19positive-test-bronx-zoo/ (Accessed on April 25, 2020)

Omura, S., and Crump, A. 2014. Ivermectin: panacea for resource-poor communities? Trends Parasitol. 30(9): 445-455.

Patel, S.K., Pathak, M., Tiwari, R., Yatoo, M.I., Malik, Y.S., Sah, R., Rabaan, A.A., Sharun, K., Dhama K., Bonilla-Aldana, D.K., Rodriguez-Morales, A.J. 2020. A vaccine is not too far for COVID-19.J Infect Dev Ctries. 14(5):450-453. doi: 10.3855/ jidc. 12744 .

Paterson, T. E., Halliwell, R. E., Fields, P. J., Louw, M. L., Louw, J. P., Ball, G. S., Pinckney, R. D., and McKibben, J. S. 2009. Treatment of caninegeneralized demodicosis: a blind, randomized clinical trial comparing the efficacy of Advocate (Bayer Animal Health) with ivermectin. Vet. Dermatol. 20(5-6): 447-455. doi: 10.1111/j.13653164.2009.00803.x

Rodriguez-Morales, A.J., Dhama, K., Sharun, K., Tiwari, R. and Bonilla-Aldana, D.K. 2020. Susceptibility of felids to coronaviruses. Vet Rec. 186(17):e21. doi: 10.1136/vr.m1671.

Sharun, K., Anjana, S., Sidhique, S. A., and Panikkassery, S. 2019a. Treatment of Sarcoptic mange infestation in rabbits with long acting injectable ivermectin. J. Parasit. Dis. 43(4), 733-736. doi: 10.1007/s12639-019-01137-z.

Sharun, K., Shyamkumar, T. S., Aneesha, V. A., Dhama, K., Pawde, A. M., and Pal, A. 2019b. Current therapeutic applications and pharmacokinetic modulations of ivermectin. Vet. World. 12(8), 1204-1211. doi: 10.14202/ vetworld.2019.1204-1211

Sharun, K., Sircar, S., Malik, Y. S., Singh, R. K., and Dhama, K. 2020a. How close is SARS-CoV-2 to canine and feline coronaviruses?. J. Small Anim. Pract. 61(8): 523-526. doi: 10.1111/jsap.13207

Sharun, K., Tiwari, R., Patel, S.K., Karthik, K., Iqbal Yatoo, M., Malik, Y.S., Singh, K.P., Panwar, P.K., Harapan, H., Singh, R.K. and Dhama, K. 2019. Coronavirus disease 2019 (COVID-19) in domestic animals and wildlife: advances and prospects in the development of animal models for vaccine and therapeutic research. Hum Vaccin Immunother. 11:1-12. doi: 10.1080/21645515.2020.1807802.

Sharun, K., Dhama, K., Patel, S. K., Pathak, M., Tiwari, R., Singh, B. R., Sah, R., Bonilla-Aldana, D. K., Rodriguez-Morales, A. J., and Leblebicioglu, H. 2020c. Ivermectin, a new candidate therapeutic against SARS-CoV-2/COVID-19. Ann. Clin. Microbiol. Antimicrob. 19(1): 23. doi: 10.1186/ s12941-020-00368-w

Sharun, K., Tiwari, R., Dhama, J. and Dhama, K. 2020d. Dexamethasone to combat cytokine storm in COVID-19: Clinical trials and preliminary evidence. Int J Surg. 82:179-181. doi: 10.1016/j. ijsu.2020.08.038.

Sharun, K., Tiwari, R., Iqbal Yatoo, M., Patel, S.K., Natesan, S., Dhama, J., Malik, Y.S., Harapan, H., Singh, R.K. and Dhama, K. 2020e. Antibody-based immunotherapeutics and use of convalescent plasma to counter COVID-19: advances and prospects. Expert Opin Biol Ther. 20(9):10331046. doi: 10.1080/14712598.2020.1796963.

Shi, J., Wen, Z., Zhong, G., Yang, H., Wang, C., Huang, B., Liu, R., He, X., Shuai, L., Sun, Z., Zhao, Y., Liu, P., Liang, L., Cui, P., Wang, J., Zhang, X., Guan, Y., Tan, W., Wu, G., Chen, H., and Bu, Z. 2020. Susceptibility of ferrets, cats, dogs, and other domesticated animals to SARS-coronavirus 2. Science. 368(6494): 1016-1020. doi: 10.1126/ science.abb7015

Sivaprasad, M., Jisna, K., Sharun, K., Faslu Rahman, C., and Faslu Rahman, A. 2020. Laboratory Diagnosis of COVID-19: Safety and Preventive Measures for Sample Processing. Trends in Biomaterials ef Artificial Organs. 34(S3): 66-69.

Tiwari, R., Dhama, K., Sharun, K., Iqbal Yatoo, M., Malik, Y. S., Singh, R., Michalak, I., Sah, R., Bonilla-Aldana, D. K., and Rodriguez-Morales, A. J. 2020. COVID-19: animals, veterinary and zoonotic links. Vet. Q. 40(1), 169-182. doi: 10.1080/01652176.2020.1766725 
USDA. 2020. USDA Statement on the Confirmation of COVID-19 in a Tiger in New York. https:// www.aphis.usda.gov/aphis/newsroom/news/ sa_by_date/sa-2020/ny-zoo-covid-19 (Accessed on April 25, 2020)

Vine, NJ., Keevill, G., and Foster, AP. 2010. Sarcoptic mange in alpacas. Vet. Rec. 167, 946-947.

$* * * * * *$ 